These data thus give limited support to the suggestion that the two histological types may have different aetiologies. Our rates of adenocarcinoma, however, were based on small numbers, and the differential increase in the rates for the two histological types was not significant. Interpretation of these incidences is also complicated by the fact that it is more difficult to detect adenocarcinoma than squamous carcinoma by cervical screening. In the two American studies adenocarcinoma as a proportion of all cervical cancers in young women was $10 \cdot 3 \%{ }^{1}$ and $13 \cdot 6 \%{ }^{2}$ in 1979-82; these compare with our figure of $7 \cdot 6 \%$ and may reflect the success of the screening programme in the United States.

There has been only one epidemiological study comparing the characteristics of patients with the two histological types of cancer, ${ }^{5}$ and we are currently conducting a case-control study of carcinoma of the cervix in young women to address this issue directly.

We thank the Oxford, Thames, and West Midlands cancer registries for supplying the data, and Cynthia Taylor and Sybil Farrell for computing and secretarial help. The Institute of Cancer Research receives support from the Cancer Research Campaign and the Medical Research Council.

1 Peters RK, Chao A, Mack TM, Bernstein L, Henderson BE. Increased frequency of adenocarcinoma of the uterine cervix in young women in Los Angeles County. $\mathcal{F N C I}$ 1986;76:423-8. 2 Schwartz SM, Weiss NS. Increased incidence of adenocarcinoma of the cervix in young women in the United States. Am f Epidemiol 1986;124:1045-7.

3 Mingeot R, Fievez C. Endocervical changes with the use of synthetic steroids. Obstet Gynecol 1974;44:53-9.

4 Dallenbach-Hellweg G. On the origin and histological structure of adenocarcinoma of the endocervix in women under 50 years of age. Pathol Res Pract 1984;179:38-50.

5 Silcocks PBS, Thornton-Jones H, Murphy M. Squamous and adenocarcinoma of the uterine cervix: a comparison using routine data. $B r \mathcal{f}$ Cancer 1987;55:321-5.

(Accepted 3 September 1987)

Section of Epidemiology, Institute of Cancer Research, Sutton, Surrey SM2 5PX

CLAIR CHILVERS, MSC, senior staff scientist

Department of Community Medicine and General Practice, Gibson Laboratories, Radcliffe Infirmary, Oxford

DAVID MANT, MB, senior registrar

Imperial Cancer Research Fund's Cancer Epidemiology Unit, Radcliffe Infirmary, Oxford

M C PIKE, PHD, director

Correspondence to: Clair Chilvers.

\section{Proteoglycan concentration in synovial fluid: predictor of future cartilage destruction in rheumatoid arthritis?}

The proteoglycans of the cartilage matrix are degraded early in the course of inflammatory joint diseases, and the fragments are liberated into the synovial fluid. These fragments can be measured in synovial fluid by an enzyme linked immunosorbent assay (ELISA). ${ }^{1}$ This assay was used to show differences in proteoglycan metabolism among diseases and also that synovial fluid proteoglycan concentrations vary considerably among patients with rheumatoid arthritis. ${ }^{2}$ This might indicate heterogeneity of the disease process and possibly predict the degree of progression of the disease and future joint destruction. We therefore studied a group of patients with rheumatoid arthritis from whom synovial fluid that had been aspirated 10 years previously was available, to see if the proteoglycan concentration at that time could be correlated with the degree of joint destruction later.

\section{Patients, methods, and results}

Thirty one specimens of knee joint synovial fluid from patients with classical or definite rheumatoid arthritis ${ }^{3}$ were selected from a batch of specimens collected in 1976-7. Radiographs of the knee joints were assessed according to the LarsenDale index,${ }^{4}$ which measures destruction on a six grade scale: where 0 denotes a normal joint and 5 the most extensive disease of cartilage and bone. The knee joints looked well preserved radiologically at the time of aspiration (LarsenDale index 0-1). Intra-articular glucocorticoid injections had not been given for three months before aspiration. At follow up during 1985-6, 21 of the 31 patients (16 women and five men) were re-examined radiographically. Five patients had died, three refused examination, and two could not be traced. Five of the 21 patients had had an arthroplasty and for them the last radiographic examination before operation (1984-5) was used. All radiographs were assessed by the same radiologist.

All knee joints were aspirated to dryness. The synovial fluid was collected in sterile tubes containing edetic acid $5 \mathrm{mmol} / \mathrm{l}$, centrifuged at $1800 \mathrm{~g}$ for 20 minutes, and then stored at $-80^{\circ} \mathrm{C}$ before ELISA, as described.

Correlations were calculated by Spearman's rank order correlation coefficient. A p value of $\leqslant 0.05$ was considered to be significant.

The knee joints with the highest synovial fluid proteoglycan concentrations a decade previously had developed the most advanced joint destruction $\left(r_{s}=0.70\right.$, $\mathrm{p}<0.002$ ) (figure). The total amount of proteoglycans, calculated by multiplying the concentration by the aspirated volume of joint fluid, also correlated with radiological progression $\left(r_{s}=0.58, p<0.01\right.$; data not shown). The median age of the 21 patients was 54 years (range 25-77 years) and the median duration of disease was 11 years (range $0 \cdot 3-30$ years) at the outset of the study. Seventeen of the patients had a positive Waaler-Rose test result.

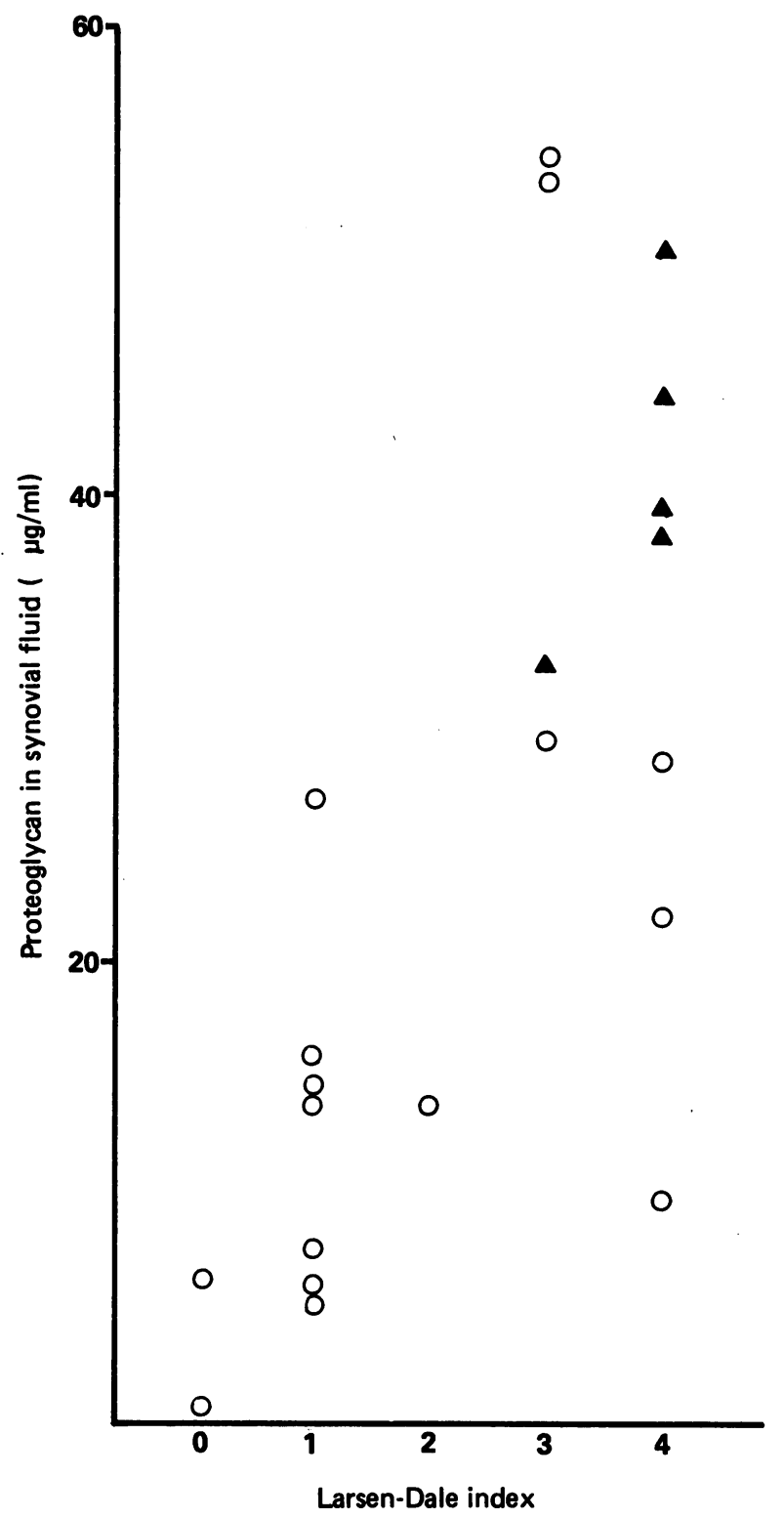

Proteoglycan concentrations in knee joint synovial fluids (collected 1976-7) and current (1985-6) degree of joint destruction measured radiographically in 21 patients $\left(r_{s}=0 \cdot 70, p<0 \cdot 002\right)$. Triangles denote patients who have had reconstructive arthroplasty.

\section{Comment}

Permanent progressive destruction of joints is a feature of rheumatoid arthritis but there is pronounced variability among patients, the reasons for which are poorly understood.

This report is the first to correlate release of a defined cartilage matrix component and later joint destruction. The results are promising and their relevance is supported by the finding of little spontaneous variation of 
proteoglycan concentrations in individual joints examined over time (T Saxne, D Heinegård, and F A Wollheim, unpublished observations). Proteoglycan concentration in synovial fluid appears not to be correlated with fluctuations in traditional signs of inflammatory activity-for example, erythrocyte sedimentation rate, and joint leucocyte count. ${ }^{2}$ Furthermore, it is unlikely that the varying rates of progression observed are due to any therapeutic intervention because neither non-steroidal anti-inflammatory drugs nor other commonly used agents have any effect on the outcome of the disease. $^{5}$

Although selected because they had normal or near normal radiographs of their knees, the patients had an initial median duration of disease of 11 years. Further studies are required to elucidate the prognostic value of proteoglycan measurements in patients with recent onset of disease.

Grants were received from Folksams Yrkesskadors Stiftelse, the Medical Research Council, the Medical Faculty, University of Lund, Kock's Stiftelser, Österlund's Stiftelse, Stiftelsen för Bistånd åt Vanföra i Skåne, Crafoord's Stiftelse, and Konung Gustaf V:s 80-årsfond. We thank Siv Valterson and Annika Björne-Persson for technical help.

1 Saxne T, Heinegard D, Wollheim FA. Therapeutic effects on cartilage metabolism in arthritis as measured by release of proteoglycan structures into the synovial fluid. Ann Rherm Dis 1986;45:491-7.

2 Saxne T, Heinegard D, Wollheim FA. Cartilage proteoglycans in synovial fluid and blood in inflammatory joint disease. Relation to systemic treatment. Arthritis Rheum 1987;30:972-80.

3 Ropes MW, Bennet GA, Cobb S, Jacox R, Jessar RA. Diagnostic criteria for rheumatoid arthritis: 1958 revision. Ann Rheum Dis 1959;18:49-53.

4 Larsen A, Dale K, Eek M. Radiographic evaluation of rheumatoid arthritis and related conditions by standard reference films. Acta Radiol (Diagn) 1977;18:481-91.

5 Pullar T, Capell HA. Can treatment really influence the radiological progression of rheumatoid arthritis? Br $\mathcal{J}$ Rheumatol 1986;25:2-6.

(Accepted 3 September 1987)

University Hospital, S-221 85 Lund, Sweden

TORE SAXNE, MD, PHD, rheumatologist

FRANK A WOLLHEIM, MD, PHD, professor of rheumatology

HOL GER PETTERSSON, MD, PHD, diagnostic radiologist

DICK HEINEGÅRD, MD, PHD, professor of physiological chemistry

Correspondence to: Dr Saxne.

\section{Percutaneous lithotripsy and endoprosthesis: a new treatment for obstructive jaundice in Mirizzi's syndrome}

In 1948 Mirizzi described a syndrome of obstructive jaundice due to impaction of a stone within the cystic duct or the neck of the gall bladder associated with stricture of the common hepatic duct. ${ }^{1}$ The accepted treatment of choledochotomy and cholecystectomy is, however, commonly difficult and hazardous. We report a new treatment consisting of percutaneous lithotripsy and insertion of an endoprosthesis through the papilla of Vater.

\section{Case report}

A previously healthy 71 year old man was referred to this hospital with a three week history of increasing malaise and deepening jaundice. He had a fever and tender hepatomegaly, and his gall bladder was palpable. Biochemical investigation showed a bilirubin concentration of $151 \mu \mathrm{mol} / \mathrm{l}$, indicating obstructive jaundice. Ultrasonography showed dilatation of the biliary tree down to the common hepatic duct with a stone obstructing the neck of the gall bladder, which was dilated. Endoscopic retrograde cholangiography showed the stone adjacent to the stricture of the common hepatic duct with upstream dilatation (figure $(a))$. A $9 \mathrm{~cm} 10$ French gauge $(3.2 \mathrm{~mm})$ polyethylene straight endoprosthesis with side flaps (Amsterdam stent) was inserted through the stricture of the common hepatic duct (figure $(b)$ ) to drain the intrahepatic biliary tree.

Percutaneous drainage of the gall bladder with a 7 French gauge $(2.4 \mathrm{~mm})$ pigtail catheter under ultrasonographic control yielded $300 \mathrm{ml}$ pus. The catheter was exchanged for a 12 French gauge $(4.0 \mathrm{~mm})$ Cope self retaining catheter and left within the gall bladder for two weeks, enabling the patient to return home for a few days. On readmission he had regained weight and was no longer clinically jaundiced (bilirubin concentration $25 \mu \mathrm{mol} / \mathrm{l}$ ).

Subsequently, under general anaesthesia and with radiographic control, the tract into the gall bladder was dilated with fascial dilators and a rigid nephroscope passed through a 26 French gauge Amplatz sheath into the gall bladder. The stone was visualised, a 5 French gauge electrohydraulic lithotripter probe (Wolf Lithotripter 2137, continuous pulse) was applied to its surface, and approximately 100 energy bursts of one second were delivered to induce fragmentation. Fragments were washed out of the gall bladder by saline irrigation around the nephroscope, and larger fragments were extracted with forceps. A

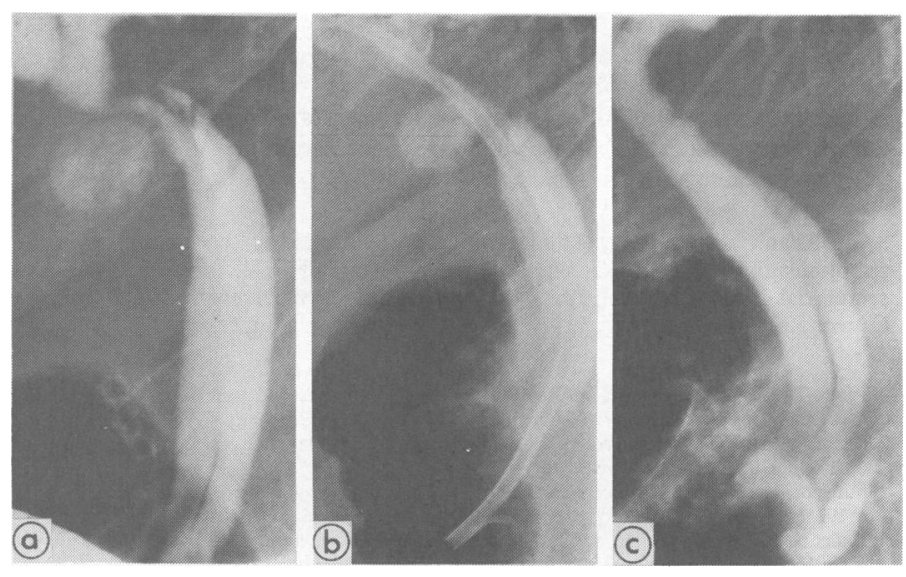

Endoscopic retrograde cholangiograms showing (a) stone adjacent to stricture of common hepatic duct; (b) Amsterdam stent traversing stricture; (c) resolution of stricture. (Ventral portion of pancreas divisum also visible.)

Foley catheter was inserted into the gall bladder before check cholecystography and then removed. The patient was discharged 48 hours after extraction of the stone. Six weeks later the endoprosthesis was removed and a cholangiogram showed complete resolution of the stricture of the common hepatic duct (figure (c)). At endoscopic sphincterotomy a small quantity of sludge was removed from the duct. The procedure was tolerated well by the patient, who was discharged 24 hours later.

\section{Comment}

This patient presented in a confused and toxic state with obstructive jaundice. He was considered to be unfit for surgery and was referred for endoscopic treatment. An endoprosthesis inserted through the papilla of Vater is currently used to treat malignant obstructive jaundice but rarely for benign biliary obstruction and choledocholithiasis. ${ }^{24}$ We were able to avoid the dangers of general anaesthesia and laparotomy by inserting an endoscopic stent to manage the stricture of the bile duct and a percutaneous tube to drain the empyema of the gall bladder.

Alternative methods of managing cholecystolithiasis include percutaneous extraction, the instillation of dissolving agents, and extracorporeal shock wave lithotripsy. ${ }^{5}$ In this case the impaction of the stone within the neck of the gall bladder ruled out the alternatives except for extracorporeal shock wave lithotripsy, which was not available.

We believe this to be the first report of electrohydraulic lithotripsy of a stone within the gall bladder and the use of an endoprosthesis to relieve obstructive jaundice in Mirizzi's syndrome; we suggest that endoscopic and percutaneous treatment should be considered in other such cases.

We thank Mr R C G Russell, Dr R Mason, and Dr D Rickards for advice and help in management and Mrs $M$ Ghilchick for referring the patient.

1 Mirizzi PL. Sindrome del conducto hepatico. Foumal International de Chirurgie 1948;8:731-77. 2 Cotton PB. Endoscopic methods for relief of malignant obstructive jaundice. World f Surg 1984;8:854-61

3 Huigbretse K. Endoscopic treatment of post-operative biliary strictures. Endoscopy 1986;18: 818-22.

4 Dias L, Cairns SR, Cotton PB. Endoscopic prosthesis for common bile duct stones. Gut 1987;28:A1371.

5 Leuschner U. Endoscopic therapy of biliary calculi. In: Classen M, ed. Clinics in gastroenterology. Philadelphia: W B Saunders, 1986:333-58.

(Accepted 9 September 1987)

\section{Middlesex Hospital, London W1N 8AA}

S R CAIRNS, MD, MRCP, senior registrar, department of gastroenterology

G N WATSON, MB, FRCS, senior registrar, department of urology

W R LEES, MB, FRCR, consultant radiologist

P R SALMON, MB, FRCP, consultant gastroenterologist

Correspondence to: Dr Cairns. 